\title{
On the Possibility of Laser Stripping of Communication Cables with Low-Power $\mathrm{CO}_{2}$ Laser
}

\author{
Lyubomir Lazov \\ Rezekne Academy of Technology \\ Rezekne, Latvia \\ Lyubomir.Lazov@rta.lv
}

\author{
Andris Snikeris \\ Rezekne Academy of Technology Rēzekne, Latvia \\ snikeris_a@protonmail.com
}

\begin{abstract}
Laser engraving is one of the most commonly used laser procedures for interacting with laser material. The speed, ease of use and high precision make it an attractive process for use by manufacturers and for removing insulation from various cables. Cable stripping is a particularly common operation in aeronautics. The aircraft is equipped with several hundred kilometers of cables to control and operate the various systems of the aircraft and most of these cables must be stripped at both opposite ends to allow the cable to be connected to different terminals.
\end{abstract}

This report examines the possibility of removing polyvinyl chloride (PVC) insulation from telecommunication cables of different colours and thicknesses up to $600[\mu \mathrm{m}]$. The experimental measurements of the study were performed with a lowpower continuous $\mathrm{CO}_{2}$ laser system. The main functional dependence of the width and depth of the ablation zone on the main technological parameters, such as the average power and the processing speed, have been experimentally studied. The zones of laser impact are observed with a laser microscope. The graphic dependencies are analyzed in order to determine the optimal working intervals.

The analysis aims to help solve problems related to the application of small diameter communication cables in the production of various communication devices and components for the needs of industry.

Keywords - ablation, cable, $\mathrm{CO}_{2}$ laser, polyvinyl chloride

\section{INTRODUCTION}

Polyvinyl chloride is one of the major types of plastics, which is widely used in various industries like electrical, automotive equipment, packaging, construction, aeronautics, and applications such as windows, flooring, bottles, pipes, fittings, cables, etc. [1]. At the global level, demand for PVC exceeds 35 million tonnes per year, and it is rated second only after polyethylene as volume leader in the plastics industry [2]. Due to its low cost and good dielectric and processing properties, PVC is one of the most widely used insulating materials [3]. It also has stable chemical properties, has excellent fire resistance due to the presence of chlorine, is easily process able, has good insulation and dielectric performance, and is environmentally friendly [4,5].

Nowadays in manufacturing, the ability to strip insulation of various materials and materials from cables or wires is very important. For "state-of-the-art" applications it is necessary to be able to strip insulation layers with high precision and efficiency, without damaging the conductor. For copper (CU) cables laser wire stripping mechanisms achieve this by their ability to selectively remove insulating material while leaving copper intact. It is very important to find a balance between the intensity of laser radiation and the preservation of cable characteristics to achieve an optimal cable stripping process.

One of the most commonly used laser types for wire-stripping systems is the $\mathrm{CO}_{2}$ laser. $\mathrm{CO}_{2}$ lasers play a large role in the laser-material processing industries. $\mathrm{CO}_{2}$ laser offers good beam quality and low cost per watt. Numerous discrete output wavelengths from 9 to 11 microns in the far-IR spectrum. Specific wavelengths can be selected with the use of isotopes in a laser gas mixture. Radiation in this wavelength is strongly absorbed by a large amount of commonly used materials including PVC [6]. 
The $\mathrm{CO}_{2}$ laser beam does not damage the conductor part of the CU cable, because copper is very reflective to the $\mathrm{CO}_{2}$ laser beam and has high thermal conductivity, but the insulating materials tend to be highly absorbing. As the laser beam passes through the cable, it cuts precisely through the insulation, which which allows easy removal of the insulating layer of the cable [7].

Martnyuk has researched the usage of frequency quadrupled Nd: YAG laser for wire stripping [8]. Iceland has researched the usage of $\mathrm{CO}_{2}$ and $\mathrm{Nd}$ :YAG lasers in wire-stripping equipment [9]. Miller has researched the ability of a $10.6[\mu \mathrm{m}] \mathrm{CO}_{2}$ laser to selectively remove the insulation of various materials [10].

The main purpose of this study is to determine the necessary parameters of a $\mathrm{CO}_{2}$ laser system to completely remove the outer isolation layer of communication cables, deriving the functional dependencies of the depth of laser ablation on power, speed, the raster step distance and influence of material's colour on twisted pair CU cables outer insulation layer made of PVC with a thickness of up to $600[\mu \mathrm{m}]$.

\section{INSULATION REMOVAL TECHNIQUES}

The cable stripping process is the removal of the insulation, which covers the electrically conducting wire or wires of a cable, to make the cable-ready insertion in the cable connector. Conventional cable stripping technologies include abrasive, chemical, thermal, and mechanical methods. Each of those methods has its drawbacks in one or several areas such as damage to a copper conductor, low precision, quality, or poor processing speed.

In precise manufacturing applications where perfect insulation removal is needed it is unacceptable to have such deficiencies. Mechanical cable-stripping methods are not well suited to strip cables that do not have regular cross-sections like twisted pair cables, which are very frequently used in telecommunications. The quality of this process highly depends upon the skill and experience of the crafts-person to cut through the protective cover without damaging or stressing the elements [11]. Twisted pair cable (TPC) is composed of two conductors which are twisted together. The twisting is used to cancel electromagnetic interference from external sources and to reduce the cross-talk with surrounding wires (typically within large bundles) and it is also used to protect the environment from its radiation [12]. Chemical cable-stripping methods have a long processing time and environmental issues. Successful thermal cable-stripping requires very precise calibration and temperature control and it needs a secondary operation to completely remove all insulation from a selected area of the cable.

Laser cable stripping has a faster processing time, better process control, and very good precision compared to other methods. Laser cable stripping is a contact-less process and using appropriate laser type and laser power is important to significantly reduce the risk of damage to the copper conducting part. The laser beam can create a variety of patterns such as cross-cut end strips, angled cuts, mini-windows, or any programmable patterns and selected points of cable or wire. A list of insulation types strippable by $\mathrm{CO}_{2}$ laser includes rubber, fabric, Teflon, polyvinyl chloride, Kapton, and fiberglass.

\section{EQUIPMENT AND MATERIALS}

ST-CC9060 laser systems were used in the experimental process for sample processing. Parameters of ST-CC9060 laser are shown in table I. This laser is specially designed for interaction with nonmetallic materials. This system has and a high-speed $\mathrm{XY}$ coordinate table, with unique fully sealed cavity construction shown in Fig. 1.

Principle of operation: the resonator tube of the $\mathrm{CO}_{2}$ laser is filled with a gas mixture as a laser-active medium. A laser discharge generates when high voltage is applied to the electrodes of the laser resonator, this process causes the molecules in the $\mathrm{CO}_{2}$ gas mixture to release laser radiation in form of emissions. After amplification, in laser resonator photons leaves it through the output resonator. These photons, who are directional, monochromatic, and coherent from the laser beam with help of optical systems are directed to the work surface.

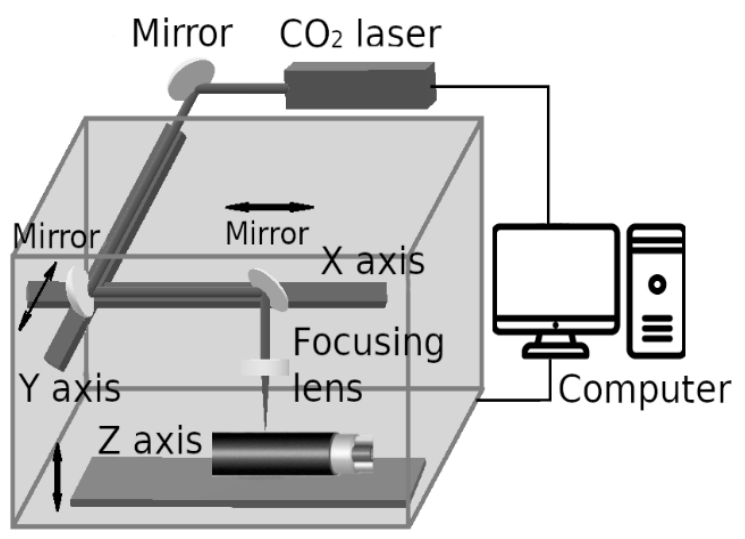

Fig. 1. Scheme of the operational stand 
Environment. Technology. Resources. Rezekne, Latvia Proceedings of the $13^{\text {th }}$ International Scientific and Practical Conference. Volume 3, 181-186

TABLE I. PARAMETERS OF ST-CC9060 LASER

\begin{tabular}{|c|c|}
\hline Laser Power $P$ & $100 \mathrm{~W}$ \\
\hline Laser Wavelength $\lambda$ & $10640 \mathrm{~nm}$ \\
\hline Marking Area $S$ & $900 \mathrm{~mm} \times 600 \mathrm{~mm}$ \\
\hline Marking Speed $v$ & $0-1000 \mathrm{~mm} / \mathrm{s}$ \\
\hline Repetition Accuracy & $\pm 0.02 \mathrm{~mm}$ \\
\hline Power Consumption & $1.5 \mathrm{~kW}$ \\
\hline Power Supply & $220 \mathrm{v} / 50 \mathrm{~Hz} / 10 \mathrm{~A}$ \\
\hline Cooling system & water cooling \& protection \\
\hline Focal Lengtem $f$ & $65 \mathrm{~mm}$ \\
\hline
\end{tabular}

For the parameter measurement of the heat-affected zone, an OLS-5000 SAF laser microscope (Fig. 2) was used. Magnification of 20x with repeatability -0.03 $[\mu \mathrm{m}]$ was used for determining the width and depth of the heat-affected zone.

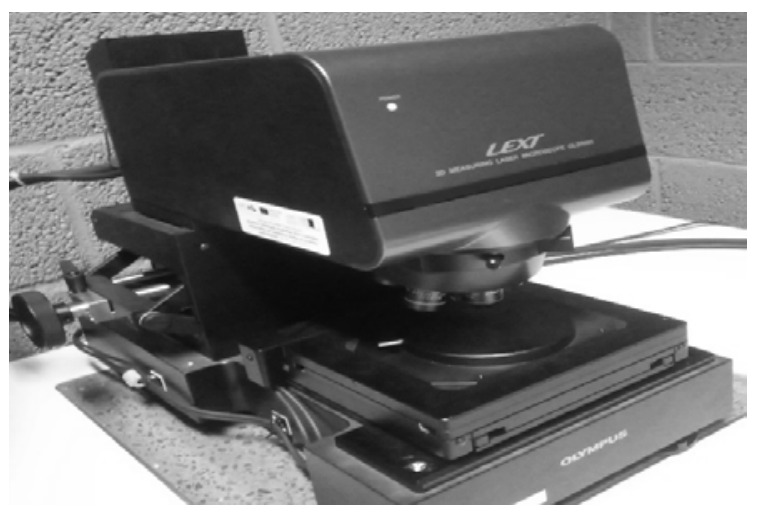

Fig. 2. OLS-5000 SAF confocal laser microscope

\section{MATERIALS / EXPERIMENTAL SAMPLES}

PVC is a thermoplastic material, meaning that it can be softening when heated and hardening when cooled and it can undergo these processes many times without any noticeable change. Properties of PVC can vary depending on its molecular weight and additives (plasticizers, fillers, pigments, etc.) PVC is extremely cost-effective in comparison to other plastics with a high degree of versatility in end-use and processing possibilities. It is durable, easily maintained, and can be produced in a variety of colours. It has good stiffness, impact strength, good chemical resistance, and non-flammability [13, 14].

There are different types of PVC available on the market which can be used as an insulation material. The most common types are rigid PVC (PVC-U) and plasticized PVC (PVC-P) PVC-P is usually used for stranded cables where the flexibility of the cable is necessary. PVC-U is used for solid cables which are more useful for heavy-duty applications [13]. The most important parameters of PVC-P and PVC-U are shown in Table II. Another important factor that influences the absorbability of laser light for PVC is the colour of the material. colour or PVC depends on the amount and type of pigment additives present in the material.

TABLE II. PARAMETERS OF RIGID AND PLASTICISED PVC [13]

\begin{tabular}{|c|c|c|}
\hline Property & Rigid & Plasticized \\
\hline Density $\left(\mathrm{g} / \mathrm{m}^{3}\right)$ & $1.34-1.39$ & $1.29-1.34$ \\
\hline $\begin{array}{c}\text { Tensile modulus } \\
(\mathrm{GPA})\end{array}$ & $2.41-2.45$ & - \\
\hline $\begin{array}{c}\text { Tensile strenght } \\
(\mathrm{MPa})\end{array}$ & $37.2-42.4$ & $14-26$ \\
\hline $\begin{array}{c}\left.\text { Density (g/m }{ }^{3}\right) \\
\text { Elongation at break } \\
(\%)\end{array}$ & $1.34-1.39$ & $1.29-1.34$ \\
\hline Notched izod (kJ/m) & $0.74-1.12$ & $250-400$ \\
\hline Hardness & $\begin{array}{c}\text { R107-R122 } \\
\text { (Rockwell) }\end{array}$ & A71-A96 (Shore) \\
\hline
\end{tabular}

\section{METHODOLOGY}

Depth $h$ of a single slit cut and $10 \times 10 \mathrm{~mm}$ window cut area was measured as a function of laser power $P$, raster step distance $\Delta x$, and processing speed $v$. PVC-P strips of different colours (white, yellow, red, green, blue and black) with a size of $20 \times 200$ [mm], thickness - 0.6 [mm] were prepared for the experimental series. The focal length $f$ and the spot size of laser beam $d$ are constant throughout the entire experimental study $-d=$ 92.7 $[\mu \mathrm{m}], f=65[\mathrm{~mm}]$. Laser interaction time $-t$ and laser power density - $W$ were measured for all measurements. Error calculation was made for all measurements. Every experiment was repeated 4 times to achieve more reliable results. A 10 x10 [mm] window cut area of each sample was performed using a raster scanning method. (Figure 3.) Raster step distance $\Delta x$ is the distance between the lines of the trajectory of the laser beam.

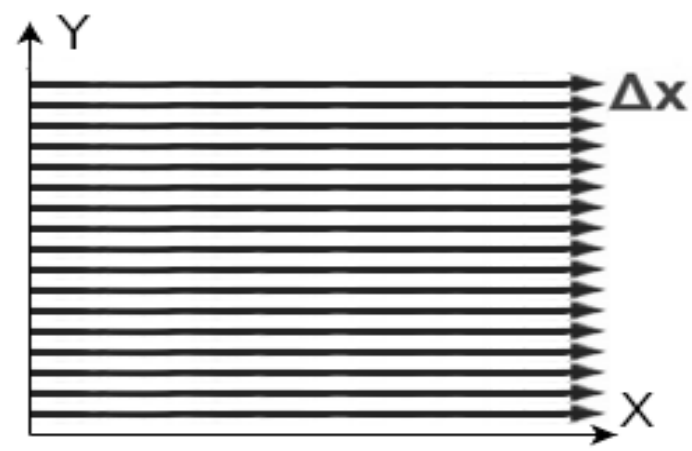

Fig. 3. Raster scanning method

Experimental part of the study is divided in four parts.

In the first section of the experimental process, ablation depth $h$ was examined as a function of processing speed $v-h=h(v)$ for $10 \times 10[\mathrm{~mm}]$ area 
ablation for samples of six different colours. Values of $P$ and $\Delta x$ are constant through experimental series. $P=$ const $=4.5,7.3,10.5,14 \mathrm{~W}, \Delta x=$ const $=20[\mu \mathrm{m}] . v=$ $100 \div 345[\mathrm{~mm} / \mathrm{s}]$

In the second section of the experimental process, ablation depth $h$ was examined as a function of laser power $P: h=h(P)$ for $10 \times 10[\mathrm{~mm}]$ area ablation for samples of six different colours. Values of laser power $P$ used in these series: $1,2.2,3.5,4.5,6.1,7.3,9,10$ [W]. Values of $v$ and $\Delta x$ are constant through experimental series. $v=$ const $=150,225$ and 300 $[\mathrm{mm} / \mathrm{s}], \Delta x=$ const $=20[\mu \mathrm{m}]$.

In the third section of the experimental process, ablation depth $h$ was examined as a function of laser power $P-h=h(P)$ for a single-slit cut samples of six different colours. Values of laser power $P$ used in these series: 1, 2.2, 3.5, 4.5, 6.1, 7.3, 9, 10, 12, 14, 17.6, 20, 23.6, 27.6, 30, 34.5, 38.5, 43 [W]. Values of $v$ and $\Delta x$ are constant through experimental series. $v=$ const $=$ $200[\mathrm{~mm} / \mathrm{s}]$.

In the fourth section of the experimental process, ablation depth $h$ was examined as a function of raster distance $\Delta x: h=h(\Delta x)$. Values of $P$ and $v$ are constant through experimental series. $P=$ const $=4.5$ [W], $v=$ const $=100[\mathrm{~mm} / \mathrm{s}], \Delta x=10 \div 80[\mu \mathrm{m}]$.

\section{RESULTS OF EXPERIMENTAL STUDIES}

Results of the first set of experiments are shown in Fig. 4 and Fig. 5. Fig. 4 shows the depth of 10x10 [mm] laser-ablated zone as a function of the laser processing speed of four different colours - white, yellow, green, and black samples to make the graph clearer. Experiments where cable isolation was fully ablated ( $h$ $>600[\mu \mathrm{m}])$ and the values of those measurements are not shown in Fig. 4.

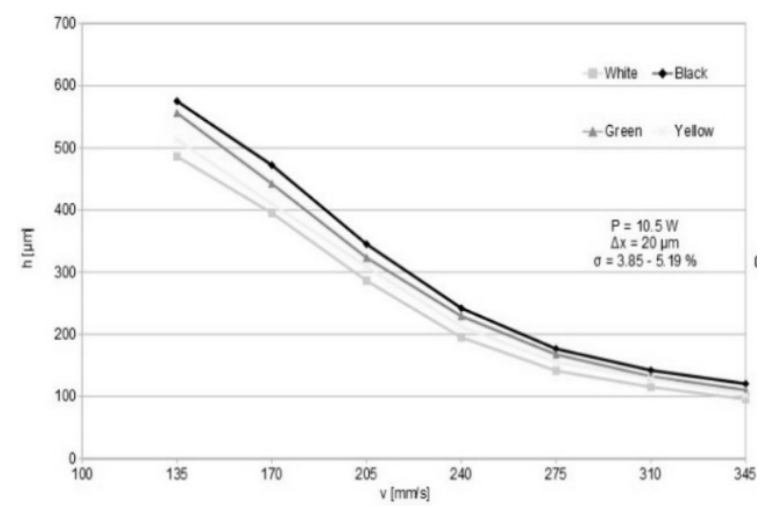

Fig. 4. Depth of the laser-ablated area as a function of laser processing speed

Data shown in Fig. 4 shows an increase of depth h of the laser-ablated zone by decreasing the laser processing speed. The trajectory of change of $h$ is similar for samples of all colors, however, whitecolored samples consistently are showing the lowest depth of laser-ablated area as black-colored samples have the deepest zone of ablation among experimental samples. Difference of $h$ between black and white sample groups are between $15.4 \%$ at $v=135 \mathrm{~mm} / \mathrm{s}$ and
$20.5 \%$ at $v=345 \mathrm{~mm} / \mathrm{s}$. Fig. 5 shows how the depth of heat-affected zone $h$ changes as a function of laser processing speed for four different values of laser power $P$.

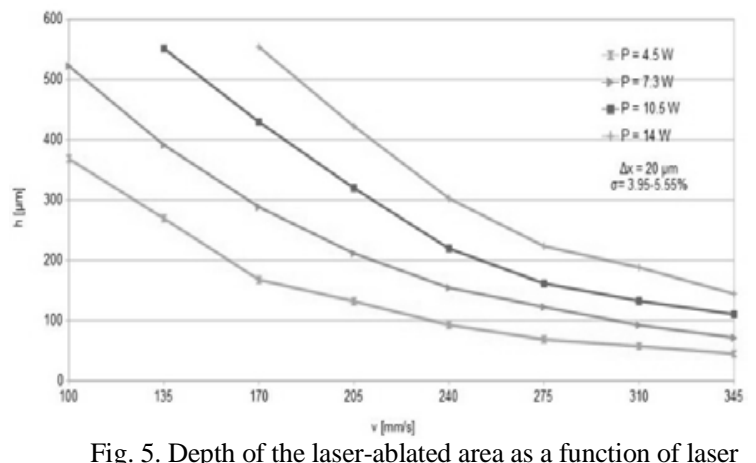

Fig. 5. Depth of the laser-ablated area as a function of laser processing speed of blue-coloured samples

A non-linear function can be observed. Changing laser power from 4.5 [W] to 14 [W] (311\% increase) depth of laser-ablated zone at measured processing speed values where does not exceed $(170-345[\mathrm{~mm} / \mathrm{s}])$ increases by 320.9 - $330.6 \%$. Depth of the laserablated zone increases proportionally to increase the laser power.

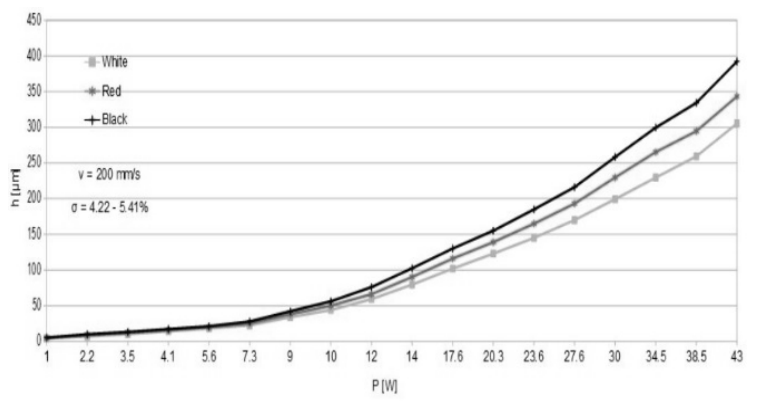

Fig. 6. Depth of the laser-ablated area as a function of laser power

Increasing laser power increases the depth of the laser-ablated zone exponentially as seen in Fig. 6. To analyze the way how increasing laser power $P$ changes the depth of the laser-ablated zone, measured results were divided into four distinct intervals. Interval $1-1$ to 10 [W]. Interval $2-10$ to 20 [W]. Interval $3-20$ to 30 [W] and interval $4-30$ to 43 [W]. Increasing $P$ of black-coloured sample in interval 1 - from 1 [W] (5.32 $[\mu \mathrm{m}])$ to $10[\mathrm{~W}](56.13[\mu \mathrm{m}])$ increases $h$ by $1055 \%$. This corresponds to a $5.65[\mu \mathrm{m}]$ increase in depth of the laser-ablated zone $h$ per 1 [W]. Increasing $P$ of the black-coloured sample in interval 2 - from 10 [W] $(56.13[\mu \mathrm{m}])$ to $20[\mathrm{~W}](155.09[\mu \mathrm{m}])$ increases $\mathrm{h}$ by $176.3 \%$. This corresponds to a $9.90[\mu \mathrm{m}]$ increase of $h$ per 1 [W]. Increasing $P$ of the black-coloured sample in interval 3 - 20 [W] $(155.09[\mu \mathrm{m}])$ to 30 [W] (258.36 $[\mu \mathrm{m}])$ increases $h$ by $66.6 \%$. This corresponds to a $10.33[\mu \mathrm{m}]$ increase of $h$ per $1[\mathrm{~W}]$. Increasing $P$ of black-coloured samples in interval 4 - 30 [W] (258.36 $[\mu \mathrm{m}])$ to $43[\mathrm{~W}](392.27[\mu \mathrm{m}])$ increases $h$ by $51.2 \%$. This corresponds to a $10.30[\mu \mathrm{m}]$ increase of $h$ per 1 [W]. 
Environment. Technology. Resources. Rezekne, Latvia Proceedings of the $13^{\text {th }}$ International Scientific and Practical Conference. Volume 3, 181-186

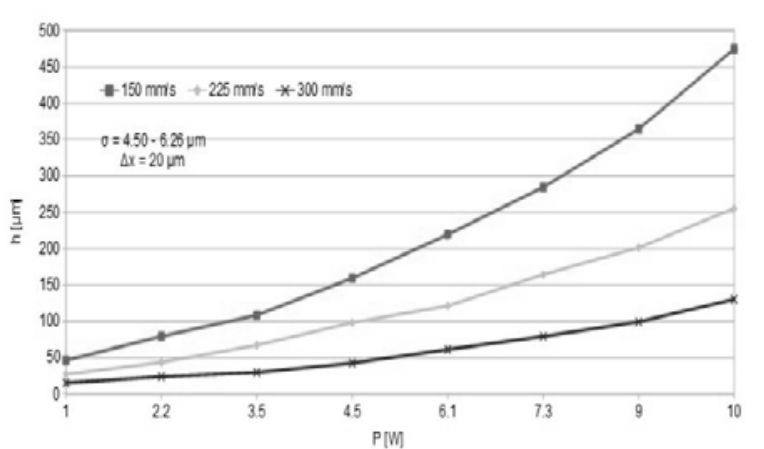

Fig. 7. Depth of the laser-ablated area as a function of laser power for three different processing speed values

Fig. 7 shows the dependence of $10 \times 10$ [mm] laserablated zone on laser power $P$ for three different laser processing speed values - 150, 225, and 300 [mm/s]. Results of red-coloured samples are shown in Figure 7 however a similar trajectory of change of $h$ is noticeable for other tested colours, but the value of $h$ slightly differs due to the absorbency of PVC plastic insulation for each colour. At $P=10$ [W], $v=150[\mathrm{~mm} / \mathrm{s}]$, depth of laser-ablated area is 3.64 times larger than at $P=10$ [W], $v=300[\mathrm{~mm} / \mathrm{s}]$.

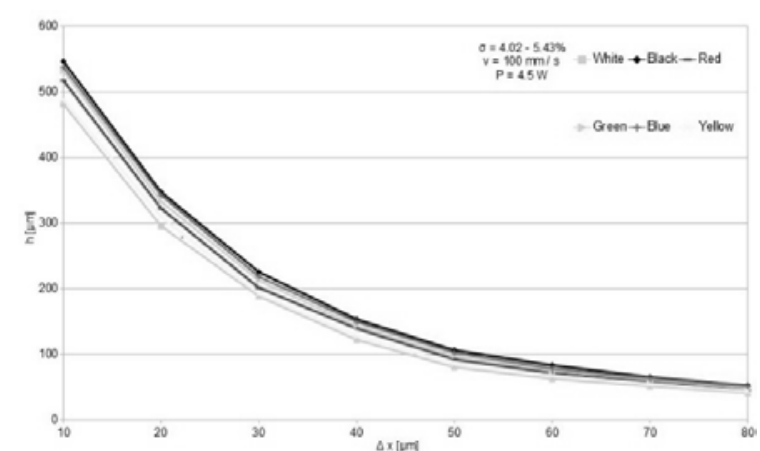

Fig. 8. Depth of the laser-ablated area as a function of raster step distance

Fig. 8 shows the dependence of the depth of laserablated area $h$ on raster step distance $\Delta x$ at $v=100$ $[\mathrm{mm} / \mathrm{s}]$ and $P=4.5[\mathrm{~W}]$ for all 6 tested colours. Due to the beam diameter $d=92.7[\mu \mathrm{m}]$ and TEM $_{00}$ laser beam, change of $h$ between $\Delta x=70[\mu \mathrm{m}]$ and $\Delta x=80$ $[\mu \mathrm{m}]$ is relatively small. As the value of $\Delta x$ is decreased further, $h$ increases exponentially.

\section{SUMMARY}

\section{The following statements can be made from the} analysis of the experiments:

- Using the selected methodology laser type and mode, it is possible to perform quick and effective ablation of commercially available telecommunication cable isolation. Laser power $P$, procession speed $v$, and raster step distance $\Delta x$ (for area ablation) are the most important parameters in the ablation process of PVC for single slit cuts and $10 \times 10$ area ablation. [15, 16] The chemical composition of specific insulation material and its colour also considerably influence the ablation process.

- $\quad$ Experimental dependencies of these parameters and depth of laser-ablated area $h$ can be used to properly adjust laser stripping of the cable insulation, depending on the thickness of the insulation layer and diameter of the cable core according to necessary safety standards, its functionality, and specific needs of a customer. These parameters can be changed at will to adjust to different insulation material, its colour, or thickness to make the process more efficient, for example, increasing processing speed $v$ and laser power $P$, adjusting raster step distance $\Delta x$.

\section{CONCLUSION:}

Finding the optimal operating parameters for specific insulation material type and thickness and understanding how a change of parameters influences the geometry of the laser-ablated area are very important steps to achieve optimal laser-material interaction. Results of this study can be of interest to different industries, which manufacturing process include cables, wires, or other applications where it is necessary to remove an area of insulating material.

The present study examines the depth of the laserablated area as a function of parameters such as laser power $P$, laser processing speed $v$, raster step distance $\Delta x$ as well as the influence of colour on the process of laser ablation on a PVC-P CU twisted pair cable outer layer isolation layer with a thickness of $600[\mu \mathrm{m}]$.

\section{REFERENCES}

[1] J. Brandrup and W. Michaeli, Eds, Recycling and recovery of plastics. Hanser Verlag, 1996.

[2] M. Sadat-Shojai, and G. R. Bakhshandeh, "Recycling of PVC wastes." Polymer degradation and stability, 96(4), 404-415, 2011. [Online]. Available: ScienceDirect, https://www.sciencedirect.com [Accessed February 25, 2021], https://doi.org/10.1016/j.polymdegradstab.2010.12.001

[3] N. M. Abdel-Gawad, A. Z. El Dein, D. E. A. Mansour, H. M. Ahmed M. M. F. Darwish, and M. Lehtonen, "Multiple enhancement of PVC cable insulation using functionalized $\mathrm{SiO} 2$ nanoparticles based nanocomposites., " Electric Power Systems Research, 163, 612-625, 2018. [Online]. Available: ScienceDirect, https://www.sciencedirect.com [Accessed February 25, 2021], https://doi.org/10.1016/j.epsr.2017.11.011

[4] K. Barber and G. Alexander, "Insulation of electrical cables over the past 50 years," IEEE Electrical Insulation Magazine, 29(3), 27-32, 2013. [Online]. Available: IEEE Xplore, https://ieeexplore.ieee.org/Xplore/home.jsp [Accessed March 1, 2021], https://doi.org/10.1109/MEI.2013.6507411

[5] W. V. Titow, “Commercial PVC Polymers.” PVC Technology (pp. 37-58). Springer, Dordrecht, 1984.

[6] A. J. DeMaria, and T.V. Hennessey, "The $\mathrm{CO}_{2}$ laser: the workhorse of the laser material processing industry,"SPIE Professional Magazine, 1-27, 2010. [Online]. Available : https://spie.org/Documents/Membership/laser_co2_demaria_ hennessey.pdf

[7] P. A. Lykov, E. V. Safonov, and A.M. Akhmedianov," Selective laser melting of copper," Materials Science Forum (Vol. 843, pp. 284-288). Trans Tech Publications Ltd, 2016. [Online]. Avaivable: Scientific.net, https://www.scientific.net 
Lazov., et al. On the Possibility of Laser Stripping of Communication Cables with Low-Power $\mathrm{CO}_{2} \mathrm{Laser}$

$\begin{array}{lcrcc}\text { [Accessed } & \text { March } & \text { 5, 2021], } \\ \text { https://doi.org/10.4028/www.scientific.net/MSF.843.284 }\end{array}$

J. Martyniuk, "UV laser-assisted wire stripping and micromachining," Lasers as Tools for Manufacturing (Vol. 2062, pp. 30-38). International Society for Optics and Photonics., 1994. [Online]. Available: SPIE Digital Library, https://www.spiedigitallibrary.org [Accessed March 3, 2021] https://doi.org/10.1117/12.167593

[9] W. F. Iceland, "Design and development of equipment for laser wire stripping," Industrial Applications of High Power Laser Technology (Vol. 86, pp. 68-72). International Society for Optics and Photonics, 1976. [Online]. Available: SPIE Digital Library, https://www.spiedigitallibrary.org [Accessed March 2, 2021], https://doi.org/10.1117/12.954963

[10] T.R. Miller, "Laser Wire Stripping”, Proc. SPIE 0744, Lasers in Motion for Industrial Applications, 1987.

[11] A.S. Cale, J.D. Danley, D.L. Dean Jr, T.L. Cooke, C.B. Mabry III, \& D.M. Miller, U.S. Patent No. 8,052,836. Washington, DC: U.S. Patent and Trademark Office, 2011.

[12] C. Jullien, P. Besnier, M. Dunand, and I. Junqua, "Advanced modeling of crosstalk between an unshielded twisted pair cable and an unshielded wire above a ground plane,” IEEE transactions on electromagnetic compatibility, 55(1), 183-194, 2012. [Online]. Available: IEEE Xplore, https://ieeexplore.ieee.org/Xplore/home.jsp [Accessed March 1, 2021], https://doi.org/10.1109/TEMC.2012.2206599

[13] S.G. Patrick, Practical Guide to Polyvinyl Chloride, 53-83, 2005.

[14] L. Lazov, A. Snikeris, I. Balchev, I. and E. Teirumnieks, "Laser marking and engraving of household and industrial plastic products”. Journal of Physics: Conference Series, 1859 (1), 012016. https://doi.org/10.1088/1742-6596/1859/1/012016

[15] L. Lazov, N. Angelov, E. Teirumnieks and E. Teirumnieka, "Preliminary numerical analysis for the role of speed onto laser technological processes”. Environment. Technology. Resources. Proceedings of the $12^{\text {th }}$ International Scientific and Practical Conference. Volume III. - Rezekne, 2019. - pp. 137. - 142. http://dx.doi.org/10.17770/etr2019vol3.4154

[16] P. Narica, L. Lazov, A. Teilans, P.Grabusts, E. Teirumnieks and P. Cacivkins, "Method for Color Laser Marking Process Optimization with the use of Genetic Algorithms". Environment. Technology. Resources. Proceedings of the $11^{\text {th }}$ International Scientific and Practical Conference. Volume II. Rezekne, 2017. - pp. 101. - 106. http://dx.doi.org/10.17770/etr2017vol2.2607 